\title{
DIFFUSION OF $\mathrm{CO}_{2}$ THROUGH POLYMER MEMBRANES
}

\author{
CHATRINE HOGSETH OLSEN ${ }^{1}$ MORTEN AUGESTAD ${ }^{2}$, IRENE HELLAND ${ }^{2}$, \\ BRITT M. E. MOLDESTAD ${ }^{1} \&$ MARIANNE S. EIKELAND ${ }^{1}$ \\ ${ }^{1}$ Department of Process, Energy and Environmental technology, University of South-Eastern Norway, Norway \\ ${ }^{2}$ Norner AS, Norway
}

\begin{abstract}
The food industry uses polymers as packaging to protect and maintain high quality and freshness of the product during distribution and storage. Polymers are permeable by gases like $\mathrm{O}_{2}, \mathrm{CO}_{2}$ and water vapour. In this paper, a suggestion for a model describing the diffusion of $\mathrm{CO}_{2}$ through different polymers used in food packaging is presented. In addition, a model describing the temperature dependency of permeation is evaluated. Relevant material constants from the literature and from experimental tests have been used. The models were developed from a theoretical study of the solution-diffusion model, and implemented in MATLAB. The suggested model describes the transmission rate of $\mathrm{CO}_{2}$ through a single layer polymeric barrier under steady state conditions at different temperatures. The polymeric material should prevent or control the diffusion of gases to maintain product quality and freshness during distribution and storage. The simulation results show a higher gas barrier for $\mathrm{CO}_{2}$ in the EVOH44 compared to the LDPE. The permeation rate increases with increasing temperature.
\end{abstract}

Keywords: $\mathrm{CO}_{2}$ diffusion, permeability coefficients, polymers, packing material.

\section{INTRODUCTION}

Polymers are common packaging materials used in the food and beverage industry. Polymers have several advantages as packaging materials being inexpensive and light weighted, easy to print, heat sealable and flexible [1], [2]. However, compared with other packaging materials like glass or metals, polymers have higher permeability. This means that low molecular weight compounds like gases, water vapour, flavour, aromas etc. will penetrate into and diffuse through the walls of the packaging material. The permeability is the transmission rate of molecules through a barrier and is one of many factors that can reduce the shelf life or damage the quality of the product inside the package. An understanding of the barrier properties of the polymer is important for selecting the appropriate polymer material for food or beverage packaging. The polymeric material should prevent or control the diffusion of gases to maintain product quality and freshness during distribution and storage. Production and handling of the packaging material are other factors that can affect the properties of the polymer [1], [3].

The degradation of food depends on time, temperature and the environment inside the packaging. Food, like fruit and vegetables, still respire after harvest and need different headspace conditions to expand their shelf life. Such an environment can be seen in a modified atmosphere packaging (MAP), where the respiration conditions are dependent on the respiratory activity, the properties of the polymer and the micro perforations. $\mathrm{CO}_{2}$ is used in the headspace of the packaging of both food and beverages. Undesirable levels of the $\mathrm{CO}_{2}$ concentration in the packages can harm the food and give a shorter shelf life. Therefore, a study of the properties of diffusion in different polymers is important [4]. Understanding the effect of the barrier properties of food packaging can thus reduce food waste and energy use.

Norner AS has developed simulation models for the oxygen (OTR) and the water vapour (WTR) transmission rate through different polymers and polymer layers. The models are incorporated in a free online calculator and describe the transport of oxygen or water vapor through different objects like bottles, films, cups and boxes. This is a valuable tool for 
industries producing and using polymers as packaging material for food and beverage. The future plan is to expand this simulation model to also include the carbon dioxide, $\mathrm{CO}_{2}$, transmission rate (CO2TR) [5].

The aim of this work is to develop a mathematical model for the diffusion of $\mathrm{CO}_{2}$ through different polymers. The model is based on relevant values found in the literature and on experimental values. A description of the empirical relation between the diffusion of $\mathrm{CO}_{2}$ and different temperatures is given for the most common polymers.

\section{TRANSPORT OF A GAS IN POLYMERIC MEMBRANES}

A membrane can be described as an interface between two phases with selective barrier properties for different gases. The transport through a non-porous membrane occurs by the solution diffusion mechanism. The partial pressure of component $i$ at the feed side is higher than the partial pressure at the permeate side, and the pressure difference acts as the driving force for the process. The deviation of Fick's law of diffusion, gives the description of the gas transport through a nonporous membrane, and is expressed by:

$$
J=-P \frac{d p_{i}}{d z}
$$

where $\mathrm{J}$ is the mole flow rate, or the flux of component $\mathrm{i}$ through the membrane, $\mathrm{P}$ is the permeability coefficient, $p_{\mathrm{i}}$ is partial pressure of component $\mathrm{i}$, and $\mathrm{z}$ is the thickness of the polymer [6]-[8].

In the solution-diffusion model, describing the gas transport under steady state conditions through a non-porous membrane, it is assumed that the solubility and diffusivity are constant, the thickness of the membrane is uniform, and that the pressure difference over the membrane is constant.

The permeability coefficient $\mathrm{P}$ varies with the morphology of the polymer and depends on many physical factors like the density, the degree of crystallinity, the glass transition temperature, the temperature, the orientation and the cross-linking. The density of the polymer can be described as the measure of free volume between the molecules and, in general, the higher density, the lower is the permeability. The crystallinity of a polymer is related to the density. Higher degree of crystallinity in the polymer gives higher density, which results in lower permeability. The glass transition temperature is the temperature at which a polymer transits from a rubbery state to a glassy state. Each polymer has a specific temperature at which the transition occurs and the properties of the polymer change. The thickness of the film will in principle not affect the permeability, diffusion or solubility. However, in the experimental tests, membranes with different thicknesses have shown differences in permeability, diffusion or solubility coefficients. This may be due to the differences in orientation and crystallinity within the polymer, and not the thickness. $\mathrm{CO}_{2}$ does not interact with the polymer, and the permeability coefficient is characteristic for the gas [7], [9].

\subsection{Mathematical model}

By multiplying the molar flux described in eqn (1) with the surface area $A$, the molar flow can be determined. Assuming ideal gas law, the change in mole concentration is given by the decrease in partial pressure of component $i$ at the high concentration side of the membrane:

$$
\frac{V}{R T} \frac{d p_{i 2}}{d t}=\frac{A P\left(p_{i 1}-p_{i 2}\right)}{z} .
$$


Integration of eqn (2) gives the partial pressure $p_{i 1}$ at the high concentration side at time t:

$$
p_{i 1}=p_{i 2}-\left(p_{i 2}-p_{i 1,0}\right) \cdot e^{-\frac{P R T A t}{z V}}
$$

where $p_{\mathrm{i} 1,0}$ is partial pressure of component $\mathrm{i}$ at the high concentration side at $t=0$. V is the volume, $\mathrm{R}$ is the gas constant and $\mathrm{T}$ is the temperature.

The temperature influences the permeation rate through the material. In general, an increase in the temperature gives an increase in the flux through the membrane. The relationship between the temperature and permeability is expressed by the Arrhenius equation [2]:

$$
P=P_{0} \cdot e^{-\left(\frac{E p}{R T}\right),}
$$

where $\mathrm{P}_{0}$ is a prefactor and $\mathrm{E}_{p}$ is the activation energy. In the literature, the prefactor and the activation energy for a polymer are given within a temperature range. For temperatures at which the permeability coefficient, prefactor and activation energy are not given, the permeability coefficients can be estimated based on a known reference value using:

$$
P_{2}=P_{1} \cdot e^{-\left(\frac{E p}{R}\right) \cdot\left(\frac{1}{T_{2}}-\frac{1}{T_{1}}\right)} .
$$

However, eqn (5) is only valid when small variations in temperature differences are used, and there is no strong interaction between the gas and the polymer. In addition, the activation energy changes over the glass transition temperature. The permeability is lower below the glass transition temperature and the Arrhenius relation gives a lower activation energy [2].

\subsection{Material constants from literature}

Literature values for the permeability coefficients of $\mathrm{N}_{2}$ and $\mathrm{CO}_{2}$ in different polymers and specified details for the given coefficients are provided in Table 1. Prefactor and activation energies for polymers found in the literature are presented in Table 2. The specified details for each value differ from each source, where the specified conditions could be related to method, relative humidity, film thickness, temperature, material structure or the standards used. The material constants for a polymer are not constant because the polymers can be processed differently, which will affect the properties and the gas transport through the polymers. Lack of information results in high uncertainty regarding the material coefficients found in the literature. However, these material coefficients were used for comparing and simulating trends in the model.

The mathematical models, describing the diffusion of $\mathrm{CO}_{2}$ through different polymers, are implemented in MATLAB. The models are based on material coefficients found in the literature and from experimental data. The suggested model describes the transmission rate of $\mathrm{CO}_{2}$ through a single layer polymeric barrier under steady state conditions and $0 \%$ relative humidity for different temperatures. The experimental values are obtained by using the standards ISO 15105-1 and DIN 53380T2 for measuring the $\mathrm{CO}_{2}$ transmission rate in LDPE at $23^{\circ} \mathrm{C}, 40^{\circ} \mathrm{C}$ and $60^{\circ} \mathrm{C}$, and in $\mathrm{PP}$ at $23^{\circ} \mathrm{C}$. The samples were conditioned for at least two days in the specified testing climate. The accuracy of the measured material constants is not specified, but due to the standards used for the measurements, these coefficients are considered as valid. 
Table 1: Experimental literature values for the permeability coefficients of $\mathrm{N}_{2}$ and $\mathrm{CO}_{2}$ in different polymers.

\begin{tabular}{|c|c|c|c|c|c|}
\hline Type Polymer & $\begin{array}{c}\mathrm{T} \\
\left({ }^{\circ} \mathrm{C}\right)\end{array}$ & $\begin{array}{c}\mathbf{T}_{g} \\
\left({ }^{\circ} \mathbf{C}\right)\end{array}$ & $\begin{array}{c}P_{\mathrm{N} 2} * 10^{13} \\
\left(\mathrm{~m}^{3} \mathrm{~m} / \mathrm{m}^{2} \mathrm{~d} \mathrm{~Pa}\right)\end{array}$ & $\begin{array}{c}P_{\mathrm{CO} 2} * 10^{13} \\
\left(\mathrm{~m}^{3} \mathrm{~m} / \mathrm{m}^{2} \mathrm{~d} \mathrm{~Pa}\right)\end{array}$ & $\begin{array}{c}\alpha \\
\mathbf{P}_{\mathrm{CO} 2} / \mathbf{P}_{\mathrm{N} 2}\end{array}$ \\
\hline LDPE [10] & 25 & $-(95-130)[14]$ & 6.1 & 86.4 & 14 \\
\hline $\mathrm{LDPE}^{4}$ [9] & 25 & & 6.3 & 82.1 & 13 \\
\hline $\operatorname{LDPE}^{1}[11]$ & 25 & & 7 & 94.6 & 13 \\
\hline $\operatorname{LDPE}^{2}[11]$ & 25 & & 7 & 104.6 & 15 \\
\hline $\operatorname{LDPE}^{3}[12]$ & 30 & & 12.3 & 228.1 & 19 \\
\hline HDPE [11] & 23 & $-(120-140)[14]$ & 2.07 & 13.4 & 6 \\
\hline HDPE [11] & 24 & & $1.5-2.3$ & $23.3-27.1$ & $12-15$ \\
\hline HDPE [10] & 25 & & 0.86 & 2.6 & 3 \\
\hline $\mathrm{HDPE}^{5}$ [9] & 25 & & 0.95 & 2.3 & 2 \\
\hline $\operatorname{HDPE}^{2}$ [11] & 25 & & 1.68 & 22.5 & 13 \\
\hline $\mathrm{HDPE}^{6}[12]$ & 30 & & 1.75 & 22.7 & 13 \\
\hline $\mathrm{PP}$ [10] & 30 & $-10[14]$ & 2.6 & 51.8 & 20 \\
\hline $\mathrm{PP}^{7}[9]$ & 30 & & 2.9 & 59.6 & 21 \\
\hline $\mathrm{PP}^{5}[12]$ & 30 & & - & 59.6 & - \\
\hline $\mathrm{PA}^{8}[11]$ & 0 & $40-87$ [14] & 0.0079 & 0.024 & 3 \\
\hline $\mathrm{PA}^{8}$ [11] & 23 & & 0.035 & 0.18 & 5 \\
\hline PA6 $^{1,8,9}[11]$ & 23 & & 0.049 & 0.32 & 6 \\
\hline PA6 [10] & 25 & & 0.06 & 0.52 & 9 \\
\hline $\mathrm{PA}^{5}$ [12] & 30 & & 0.065 & 1.04 & 16 \\
\hline $\mathrm{PA}^{8}$ [11] & 50 & & 0.46 & 1.71 & 4 \\
\hline \begin{tabular}{|l|} 
Ethylene vinyl \\
alcohol \\
EVOH 44 \\
{$[11]$} \\
\end{tabular} & 5 & 53 [14] & - & 0.002 & - \\
\hline EVOH 44 [11] & 23 & & 0.00031 & 0.008 & 25 \\
\hline $\begin{array}{l}\mathrm{EVOH}^{1} 44 \\
{[13]} \\
\end{array}$ & 25 & & 0.00026 & 0.014 & 54 \\
\hline EVOH 44 [11] & 35 & & 0.00099 & 0.02 & 20 \\
\hline
\end{tabular}

${ }^{1}$ Measured at $0 \% \mathrm{RH},{ }^{2}$ measured at STP, ${ }^{3}$ some crystallinity, ${ }^{4}$ density of $0.914 \mathrm{~g} / \mathrm{cm}^{3},{ }^{5}$ crystalline, ${ }^{6}$ density of 0.964 $\mathrm{g} / \mathrm{cm}^{3},{ }^{7}$ density of $0.907 \mathrm{~g} / \mathrm{cm}^{3}$ and $50 \%$ crystallinity, ${ }^{8}$ measured at STP and $0 \% \mathrm{RH},{ }^{9}$ for finding $\mathrm{P}_{\mathrm{CO} 2}$ DIN53380 are used and for finding $\mathrm{P}_{\mathrm{N} 2}$ DIN53122 are used, the thickness of the membrane is $0.05 \mathrm{~mm}$. 
Table 2: The prefactors and activation energies for polymers found in the literature [9].

\begin{tabular}{|c|c|c|c|c|}
\hline Polymer & Permeant & $\begin{array}{l}\text { Temperature range } \\
\left({ }^{\circ} \mathrm{C}\right)\end{array}$ & $\begin{array}{c}\mathbf{P}_{0} * 10^{13} \\
\left(\mathbf{m}^{3} \mathbf{m} / \mathbf{m}^{2} \text { day Pa }\right)\end{array}$ & $\underset{(\mathrm{kJ} / \mathrm{mole})}{\mathbf{E}_{\mathrm{p}}}$ \\
\hline \multicolumn{5}{|c|}{ Low density polyethylene (LDPE) $0.914 \mathrm{~g} / \mathrm{cm}^{3}$} \\
\hline & $\mathrm{CO}_{2}$ & $5-60$ & 535.7 & 38.9 \\
\hline & $\mathrm{N}_{2}$ & $5-60$ & 2842.6 & 49.4 \\
\hline \multicolumn{5}{|c|}{ High density polyethylene (HDPE) $0.964 \mathrm{~g} / \mathrm{cm}^{3}$} \\
\hline & $\mathrm{CO}_{2}$ & $5-60$ & 0.437 & 30.1 \\
\hline & $\mathrm{N}_{2}$ & $5-60$ & 8.56 & 39.7 \\
\hline \multicolumn{5}{|c|}{ Polypropylene (PP) $0.907 \mathrm{~g} / \mathrm{cm} 3,50 \%$ crystallinity } \\
\hline & $\mathrm{CO}_{2}$ & $20-70$ & 207.4 & 38.1 \\
\hline & $\mathrm{N}_{2}$ & $20-70$ & 11059.2 & 55.7 \\
\hline \multicolumn{5}{|c|}{$\begin{array}{l}\text { Poly(imino-1-oxohexamethylene) Nylon } 6 \\
\text { (PA6) [7] }\end{array}$} \\
\hline & $\mathrm{CO}_{2}$ & $0-90$ & 10.4 & 40.6 \\
\hline & $\mathrm{N}_{2}$ & $0-90$ & 9.1 & 46.9 \\
\hline
\end{tabular}

\section{RESULTS}

In the analysis, $\mathrm{CO}_{2}$ permeation through different polymers and the temperature dependency for the permeation are evaluated. The results from the experimental tests are compared with literature values.

\subsection{Simulation of the $\mathrm{CO}_{2}$ permeation rate}

The permeability coefficients presented in Table 3 are used in the simulations of the partial pressure of $\mathrm{CO}_{2}$ versus time for different polymers at $25^{\circ} \mathrm{C}$. The model presented in eqn (3) is used and the results are presented in Fig. 1. An initial $\mathrm{CO}_{2}$ pressure of $4 \mathrm{~atm}$ at the high concentration side is specified in the simulations; this is a typical pressure within beverage bottles. The partial pressure of $\mathrm{CO}_{2}$ at the low concentration side is assumed constant at $3.75 \times 10^{-4} \mathrm{~atm}$, which is approximately the concentration of $\mathrm{CO}_{2}$ in the atmosphere.

Table 3: Permeability coefficients used for simulation.

\begin{tabular}{|c|c|c|}
\hline Polymer & $\begin{array}{c}\text { Temperature } \\
\left({ }^{\circ} \mathbf{C}\right)\end{array}$ & $\begin{array}{c}\mathbf{P} \mathbf{c o 2} \times \mathbf{1 0}^{\mathbf{1 3}} \\
\left(\mathbf{m}^{\mathbf{3}} \mathbf{m} / \mathbf{m}^{\mathbf{2}} \mathbf{d a y} \mathbf{P a}\right)\end{array}$ \\
\hline LDPE [9] & 25 & 82.1 \\
\hline HDPE [9] & 25 & 2.33 \\
\hline PA6 [10] & 25 & 0.52 \\
\hline EVOH44 [13] & 25 & 0.014 \\
\hline
\end{tabular}




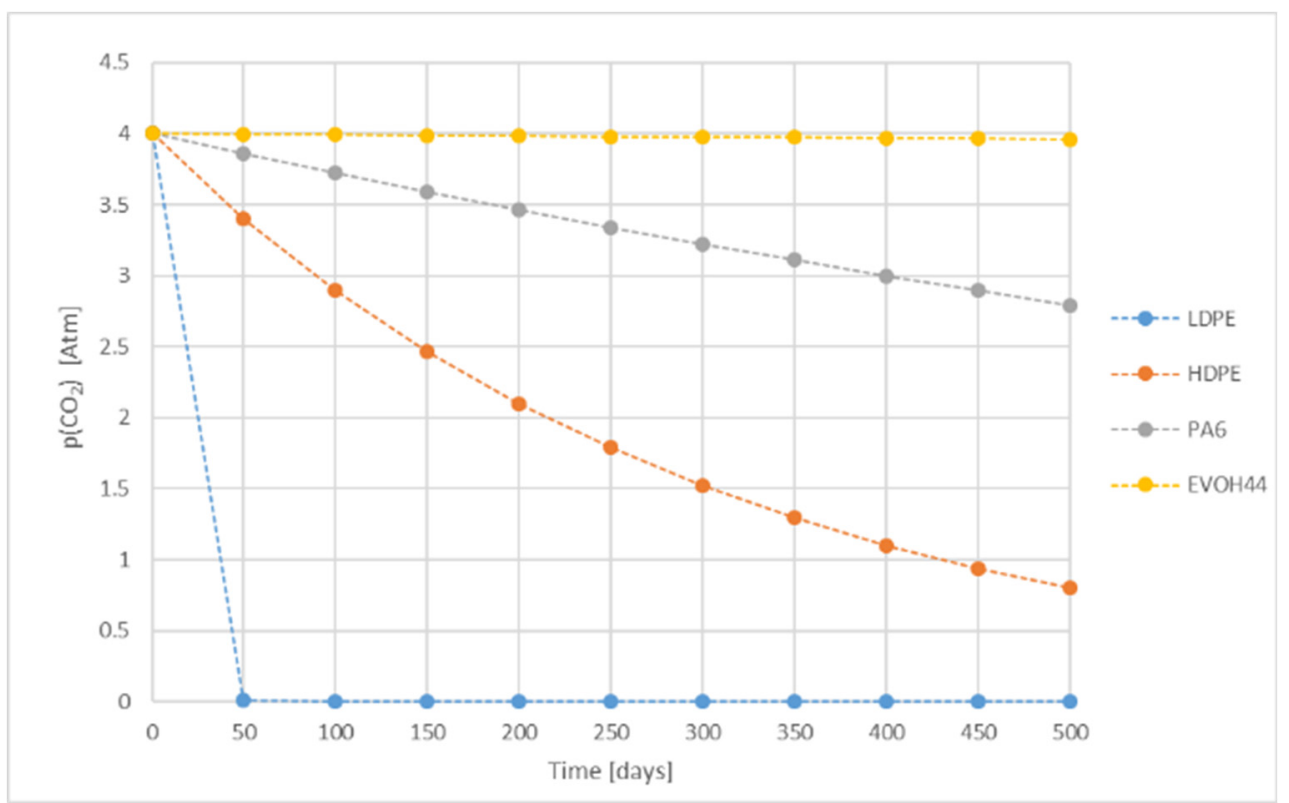

Figure 1: Change in partial pressure of $\mathrm{CO}_{2}$ at the high concentration side over time in different polymers at $25^{\circ} \mathrm{C}$.

The results show a higher gas barrier for $\mathrm{CO}_{2}$ through EVOH44 compared to LDPE. Based on the model, it will take approximately fifty days for the $\mathrm{CO}_{2}$ concentration at the high concentration side to be in equilibrium with the $\mathrm{CO}_{2}$ concentration in the atmosphere when LDPE is used. For EVOH44, the pressure inside the bottle are constant during the 500 days of simulation.

\subsection{Temperature dependency}

In order to simulate the temperature dependency of the permeability coefficients in a polymer, the activation energy must be calculated from eqn (4). The equation is used to determine the activation energy in a temperature range.

The permeability coefficients used to calculate the activation energy for PA6 are found in the literature, and presented in Table 4. The glass transition temperature for PA6 is $50^{\circ} \mathrm{C}$. The activation energy is calculated to be $62.6 \mathrm{~kJ} / \mathrm{mole}$, and is used to simulate the temperature dependency of the permeability coefficients for PA6. The simulations were performed in a temperature range of $0-50^{\circ} \mathrm{C}$, and the results are presented in Fig. 2.

Table 4: Permeability coefficients for $\mathrm{CO}_{2}$ in PA6 at different temperatures [11].

\begin{tabular}{|l|c|c|}
\hline \multicolumn{1}{|c|}{ Polymer } & Temperature $\left({ }^{\circ} \mathbf{C}\right)$ & PCo2 $\times \mathbf{1 0}^{\mathbf{1 3}}\left(\mathbf{m}^{\mathbf{3}} \mathbf{m} / \mathbf{m}^{\mathbf{2}}\right.$ dayPa $)$ \\
\hline PA6 & 0 & 0.024 \\
\hline PA6 & 23 & 0.18 \\
\hline PA6 & 50 & 1.71 \\
\hline
\end{tabular}


The simulations indicate an increase in the permeability coefficient of $\mathrm{CO}_{2}$ when increasing the temperature in the range of $0-50^{\circ} \mathrm{C}$ for PA6. The permeability coefficients presented in Fig. 2 are listed in Table 5 together with the permeability coefficients of $\mathrm{CO}_{2}$ in PA6 found in the literature. The permeability coefficients based on the model are lower than coefficient presented in literature for some of the temperatures. This can be due to the structure and properties of the measured polymer, or the method used for estimating the permeability factor.

The permeability coefficients for $\mathrm{CO}_{2}$, given in Table 5, are used in eqn (5) to study the transmission rate of $\mathrm{CO}_{2}$ through the PA6 polymer. The change in the partial pressure of $\mathrm{CO}_{2}$ as function of time is shown in Fig. 3. The figure shows that the transmission rate of $\mathrm{CO}_{2}$ through PA6 increases with increasing temperature.

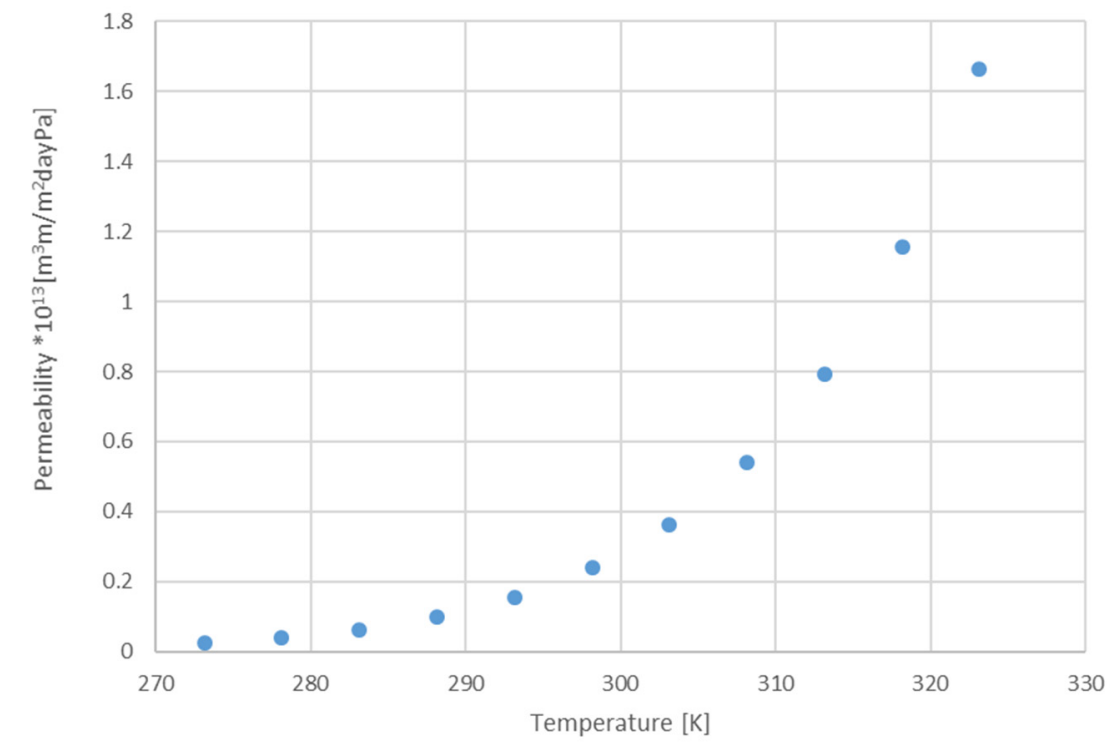

Figure 2: Permeability coefficients of $\mathrm{CO}_{2}$ in PA6 in the temperature range $0-50^{\circ} \mathrm{C}$.

Table 5: Permeability coefficients of $\mathrm{CO}_{2}$ in PA6 from the model compared with literature.

\begin{tabular}{|c|c|c|c|}
\hline $\begin{array}{c}\text { Temperature } \\
\left({ }^{\circ} \mathbf{C}\right)\end{array}$ & $\begin{array}{c}\text { Temperature } \\
(\mathbf{K})\end{array}$ & $\begin{array}{c}\text { Permeability } \times \mathbf{1 0}^{\mathbf{1 3}} \\
\mathbf{m o d e l} \\
\left(\mathbf{m}^{\mathbf{3}} \mathbf{m} / \mathbf{m}^{\mathbf{2}} \mathbf{d a y P a}\right)\end{array}$ & $\begin{array}{c}{\text { Permeability } \times \mathbf{1 0}^{\mathbf{1 3}}}^{\mathbf{}} \\
\text { literature } \\
\left(\mathbf{m}^{\mathbf{3}} \mathbf{\mathbf { m }} \mathbf{m}^{\mathbf{2}} \mathbf{\text { dayPa}}\right)\end{array}$ \\
\hline 0 & 273.15 & 0.024 & $0.024[11]$ \\
\hline 23 & 296.15 & 0.204 & $0.18[11], 0.32[11]$ \\
\hline 25 & 298.15 & 0.242 & $0.52[10]$ \\
\hline 30 & 303.15 & 0.367 & $1.04[12]$ \\
\hline 50 & 323.15 & 1.71 & $1.71[11]$ \\
\hline
\end{tabular}




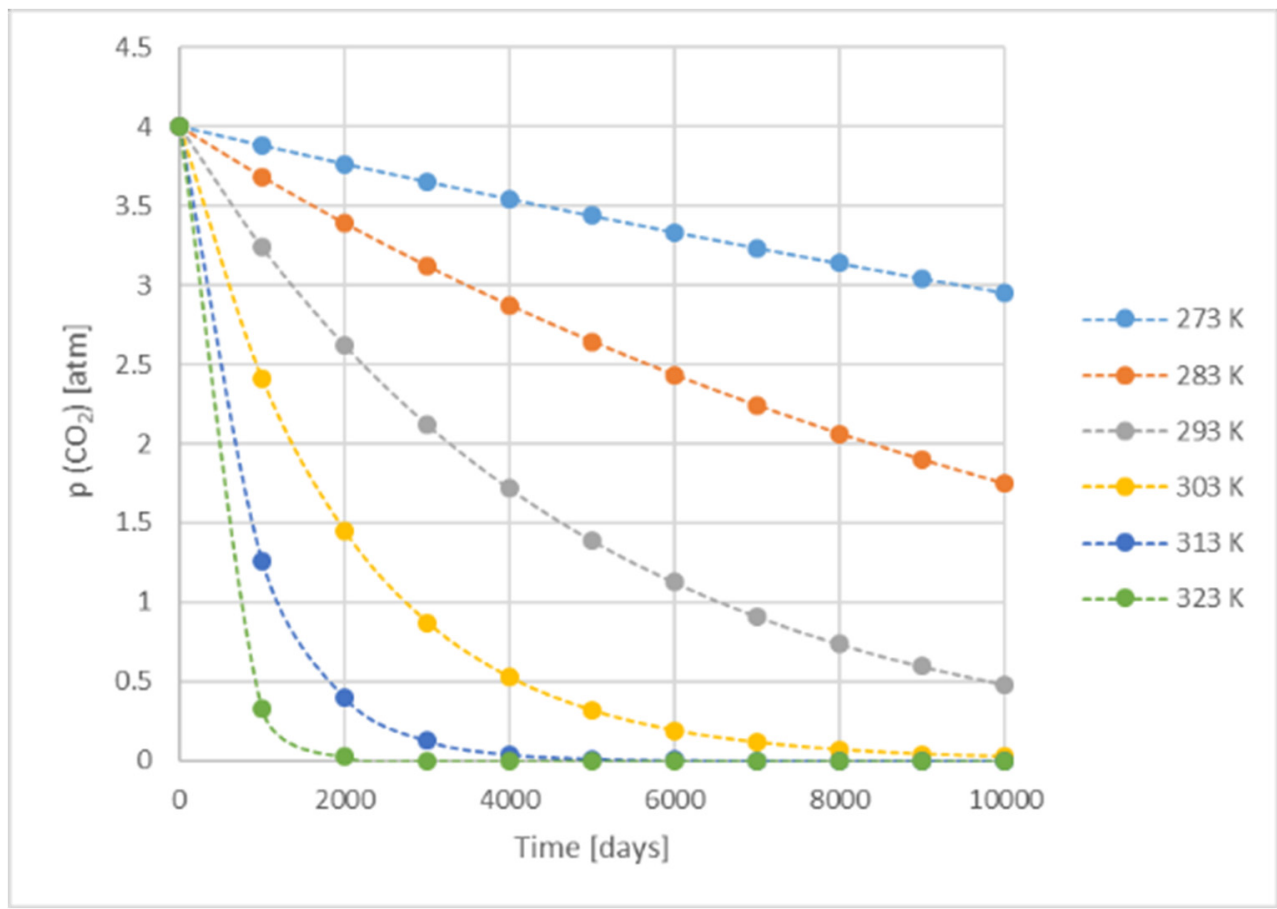

Figure 3: Change in partial pressure of $\mathrm{CO}_{2}$ at the high concentration side over time through PA6 in the temperature range $0-50^{\circ} \mathrm{C}$.

\subsection{Experimental results}

The permeability coefficients of $\mathrm{CO}_{2}$ for LDPE and PP are presented in Table 6. Each of the samples has been tested twice using an average thickness of the membrane. The permeability coefficients were further used for finding the prefactor and the activation energy for LDPE. Comparison between the measured results and the literature data is shown in Table 7 . The measured coefficients are smaller than the values from the literature. This can be due to differences in the structure and the properties of the polymers, and due to the method used for estimating the permeability coefficients. Notice that the experimental tests of LDPE have been performed at 23,40 and $60^{\circ} \mathrm{C}$. These temperatures were chosen to study how the permeability coefficient changed with temperature. PP has only been tested at $23^{\circ} \mathrm{C}$.

Table 6: Test result from experimental analysis.

\begin{tabular}{|l|c|c|c|c|c|}
\hline & & \multicolumn{2}{|c|}{ Test 1 } & \multicolumn{2}{c|}{ Test 2 } \\
\hline Film & $\begin{array}{c}\mathbf{T} \\
\left({ }^{\circ} \mathbf{C}\right)\end{array}$ & $\begin{array}{c}\text { Thickness } \\
(\boldsymbol{\mu m})\end{array}$ & $\begin{array}{c}\mathbf{P} \times \mathbf{1 0}^{\mathbf{1 3}} \\
\left(\mathbf{m}^{\mathbf{3}} \mathbf{m} / \mathbf{m}^{\mathbf{2}} \text { day Pa) }\right.\end{array}$ & $\begin{array}{c}\text { Thickness } \\
(\boldsymbol{\mu m})\end{array}$ & $\begin{array}{c}\mathbf{P} \times \mathbf{1 0}^{\mathbf{1 3}} \\
\left(\mathbf{m}^{\mathbf{3}} \mathbf{m}_{\mathbf{m}} \mathbf{m}^{\mathbf{2}} \mathbf{d a y} \mathbf{P a}\right)\end{array}$ \\
\hline LDPE & 23 & 124 & 55.3 & 113 & 57.3 \\
\hline PP & 23 & 250 & 20.5 & 252 & 20.2 \\
\hline LDPE & 40 & 124 & 119 & 113 & 124.3 \\
\hline LDPE & 60 & 124 & 235.6 & 113 & 237.3 \\
\hline
\end{tabular}


Table 7: Permeability coefficients compared.

\begin{tabular}{|c|c|c|c|c|}
\hline & & Literature & $\begin{array}{c}\text { Experimental } \\
\text { Test } 1\end{array}$ & $\begin{array}{c}\text { Experimental } \\
\text { Test } 2\end{array}$ \\
\hline Polymer & $\mathbf{T}\left({ }^{\circ} \mathrm{C}\right)$ & \multicolumn{3}{|c|}{$P_{\mathrm{CO} 2} \times 10^{-13}\left(\mathrm{~m}^{3} \mathrm{~m} / \mathrm{m}^{2}\right.$ dayPa $)$} \\
\hline LDPE [10] & 25 & 86.4 & & \\
\hline LDPE [9] & 25 & 82.1 & & \\
\hline LDPE [11] & 25 & 94.6 & & \\
\hline LDPE [12] & 30 & 228.1 & & \\
\hline LDPE & 23 & & 55.3 & 57.3 \\
\hline LDPE & 40 & & 119 & 124.3 \\
\hline LDPE & 60 & & 235.6 & 237.3 \\
\hline PP & 23 & & 20.5 & 20.2 \\
\hline PP [10] & 30 & 51.8 & & \\
\hline $\mathrm{PP}[9]$ & 30 & 59.6 & & \\
\hline
\end{tabular}

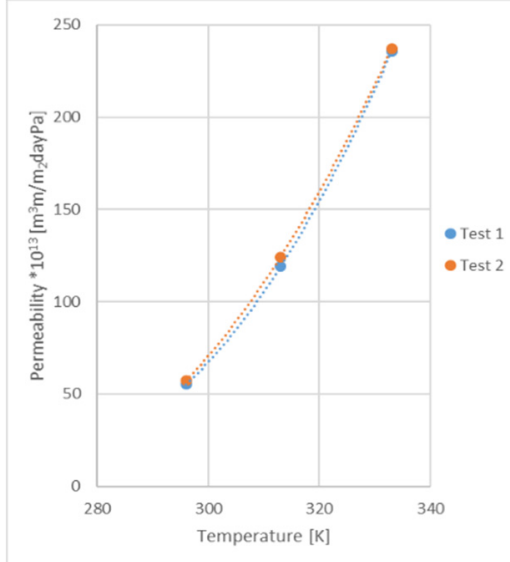

(a)

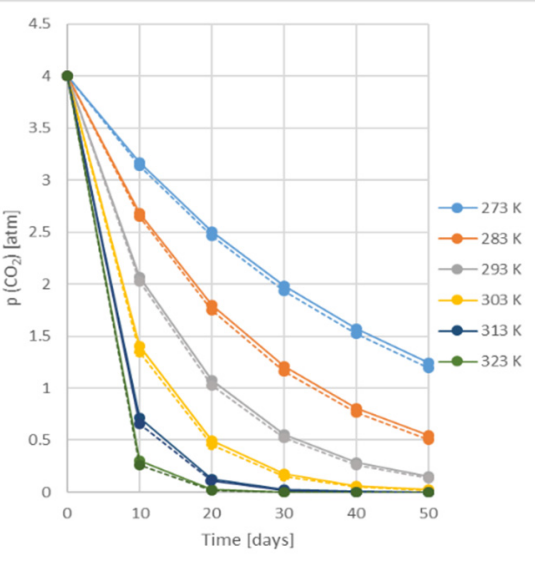

(b)

Figure 4: (a) The permeability coefficient of $\mathrm{CO}_{2}$ through LDPE; (b) The change in partial pressure of $\mathrm{CO}_{2}$ at the high concentration side versus time through LDPE at different temperatures. (Solid line: Test 1; Dotted line: Test 2).

To find the activation energy for LDPE, the experimental measurements are used. The activation energy was calculated to be $32.1 \mathrm{~kJ} / \mathrm{mole}$ for Test 1 and $31.5 \mathrm{~kJ} / \mathrm{mole}$ for Test 2 . The activation energies were further used for simulating the temperature dependence of the permeability coefficients for LDPE presented in Fig. 4. The permeability coefficients for LDPE, in both Test 1 and Test 2, are simulated within a temperature range of 0 to $50^{\circ} \mathrm{C}$. The permeability coefficients from the two experimental tests show a good consistency. The tendency is that the permeability coefficient increases with increasing temperature. The experimental data are curve-fitted in Fig. 4(a). Fig. 4(b) describes the effect of temperature on the partial pressure of $\mathrm{CO}_{2}$ for Test 1 and Test 2 . An increased temperature and permeability coefficient give an increased transmission rate of $\mathrm{CO}_{2}$. 
Fig. 5 shows a comparison of the models using the permeability coefficients of $\mathrm{CO}_{2}$, at $25^{\circ} \mathrm{C}$ and $30^{\circ} \mathrm{C}$ for LDPE. The permeability coefficients of $\mathrm{CO}_{2}$ for the experiments at $25^{\circ} \mathrm{C}$ and $30^{\circ} \mathrm{C}$ are calculated by interpolation. The permeability constants found in the literature are higher than the experimental values, which results in a slower transmission rate of $\mathrm{CO}_{2}$ in the materials analysed in this study. The simulated curves for the transmission rate of $\mathrm{CO}_{2}$ follow the same trends as the model.

3.4 Comparison of the transmission rate of $\mathrm{CO}_{2}$ through polypropylene at $25^{\circ} \mathrm{C}$

The permeability coefficient of $\mathrm{CO}_{2}$ for polypropylene (PP) from the experimental tests was measured at $23^{\circ} \mathrm{C}$, while the literature values are given at $30^{\circ} \mathrm{C}$. Fig. 6 shows the change in partial pressure of $\mathrm{CO}_{2}$ in PP versus time for the experimental tests and literature values estimated at $25^{\circ} \mathrm{C}$. The deviation in the transmission rate from the experimental test and references [9] and [10] can be due to differences in density and crystallinity of the polymers.

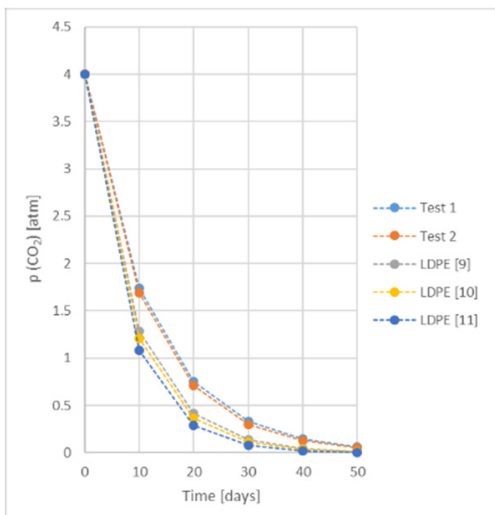

(a)

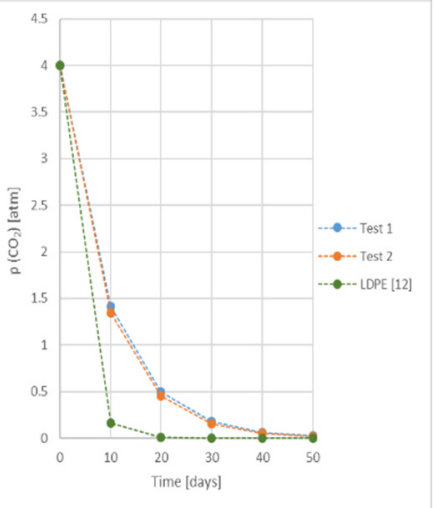

(b)

Figure 5: Comparison of the change in partial pressure of $\mathrm{CO}_{2}$ at the high concentration side over time through LDPE at (a) $25^{\circ} \mathrm{C}$; and (b) $30^{\circ} \mathrm{C}$, using the permeability coefficients from experimental tests and from the literature.

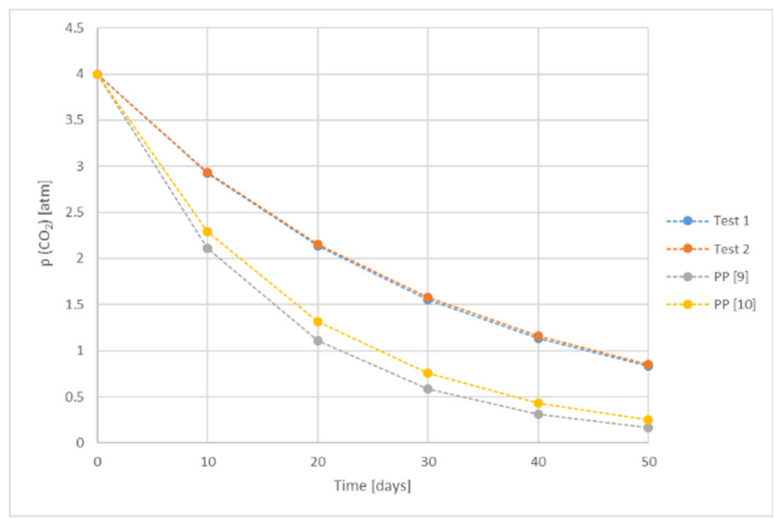

Figure 6: Change in partial pressure of $\mathrm{CO}_{2}$ at the high concentration side over time, at $25^{\circ} \mathrm{C}$. 


\section{DISCUSSION}

This paper presents a model for diffusion of $\mathrm{CO}_{2}$ through different polymers used in food packaging. The material constants used in the model were found either from the literature or from experimental tests. The model is based on mathematical relations and empirical values, which makes the model more accurate and useful.

For developing a mathematical model for the diffusion of $\mathrm{CO}_{2}$ through a polymeric membrane based on empirical relations, different assumptions were adopted. The model for the transmission rate of $\mathrm{CO}_{2}$ through polymer membranes is considered for a single polymer layer under steady state conditions in an environment of $0 \%$ humidity using different temperatures. However, in a model for polymers used for the packing of microbial sensitive foods (high humidity foods) or for carbonated drinks, a relative humidity different from $0 \%$ would be more appropriate. In such cases, the average humidity is closer to $80 \%$ than to dry conditions. The model considers only the diffusion of $\mathrm{CO}_{2}$ through the membrane, and neglects the emerging of $\mathrm{CO}_{2}$ into the product inside the packaging. $\mathrm{CO}_{2}$ can react with water and form carbon acid, which can harm the product and affect the properties of the polymeric packaging.

The system was considered as an ideal system where the solubility and diffusivity are constant due to low concentrations of the gas. Polymer films can vary in thickness, which can affect the permeation rate of $\mathrm{CO}_{2}$, and the thickness is therefore considered as uniform in this model. The ideal model is highly valid for polymers in their rubbery state because of the assumed Henry's sorption isotherm used in the solubility equation. In the glass transition state, the accuracy of the model is not considered. The polymeric barrier is considered as homogeneous, which means that the pressure is uniform through the whole membrane thickness and all mass transport occurs only in the x-direction across the membrane thickness. Mass transport that occurs in other directions, e.g. along the membrane, is low compared to the transport across a thin polymer film. The mass transport through a polymer depends on different properties of the membrane and the material constants should be determined experimentally to obtain a good validation of the model. The temperature dependency model based on the Arrhenius relation gives good agreement with experimental data and literature values. Further studies including experimental material coefficients for all polymers should be performed.

The model predicting the transmission rate of $\mathrm{CO}_{2}$ inside a polymeric packaging gives a good description of the gas diffusion. The model does not consider what is inside the packaging, only the gas transport through the polymers. From the simulations of the model, using the material coefficients found in literature compared with the measured material coefficients, it was observed that the results were following the same trends. Using more experimental data and studies of other properties, like humidity, will make the model more accurate and complete.

\section{CONCLUSION}

A model for diffusion of $\mathrm{CO}_{2}$ through different polymers was developed based on a theoretical study of the gas transport in polymeric membranes. Relevant material factors were found from literature and from experimental tests. From the theoretical study of the gas transport through polymer membranes, it was found that the permeability coefficient depends on many properties. High temperatures and relative humidity increase the permeability coefficient of $\mathrm{CO}_{2}$ in polymers, while high density and the degree of crystallinity decrease the permeability coefficient. The results from experimental tests are reliable and are used for validation of the model. There is a good agreement between material coefficients found in literature and measured material coefficients. 
The temperature dependency of the permeability coefficient of $\mathrm{CO}_{2}$ is modelled using the relations from Arrhenius. The temperature dependency model shows a good consistency between transmission rate and temperature. The suggested model for diffusion of $\mathrm{CO}_{2}$ through different polymers used in food packaging, describes the transmission rate of $\mathrm{CO}_{2}$ through polymeric barriers using a single polymer layer, under steady state conditions and in an environment of $0 \%$ relative humidity for different temperatures. The model can be used for estimations of diffusion of $\mathrm{CO}_{2}$ through polymer membranes.

To achieve a higher accuracy of the model, more experimental data are needed. Study of the effect of humidity, density and crystallinity on the diffusion of $\mathrm{CO}_{2}$ through polymers, is recommended for further work.

\section{REFERENCES}

[1] Siracusa, V., Review article food packaging permeability behaviour: A report. International Journal of Polymer Science, 2012. https://doi.org/10.1155/2012/302029.

[2] Marsh, K. \& Bugusu, B., Food packaging - roles, materials, and environmental issues. Journal of Food Science, 72(3), pp. R39-R55, 2007. https://doi.org/10.1111/j.17503841.2007.00301.x.

[3] Norner, A.S., Packaging testing and Solutions. www.norner.no/consumables/ packaging-testing-and-solutions. Accessed on: 28 Apr. 2020.

[4] Larsen, H. \& Liland, K.H., Determination of $\mathrm{O}_{2}$ and $\mathrm{CO}_{2}$ transmission rate of whole packages and single perforations in micro-perforated packages for fruit and vegetables. Journal of Food Engineering, 119(2), pp. 271-276, 2013. https://doi.org/10.1016/j.jfoodeng.2013.05.035.

[5] Norner, A.S., OTR, WVTR and CO2TR Barrier Calculator. www.norner.no/consumables/packaging-testing-and-solutions/otr-wvtr-and-co2trbarrier-calculator. Accessed on: 28 Apr. 2020.

[6] McKeen, L., Film Properties of Plastics and Elastomers, 4th ed., Elsevier Inc: Cambridge, MA, 2017.

[7] Mulder, M., Basic Principles of Membrane technology, 2nd ed., Kluwer Academic Publishers: The Netherlands, 2003.

[8] Eikeland, M.S., Durability of selected membrane materials when exposed to chlorine gas. Doctoral thesis, Telemark University College, 2001.

[9] Brandrup, J., Immergut, E.H. \& Grulke, E.A., Polymer Handbook, 4th ed., John Wiley and Sons: New York, 1999. https://doi.org/10.1002/10970126(200007)49:7<807::AID-PI436>3.0.CO;2-1.

[10] Goodfellow, Material properties, 2007. http://www.goodfellow.com. Accessed on: 02 May 2020.

[11] Massey, K., Permeability Properties of Plastics and Elastomers. A Guide to Packaging and Barrier Materials, 2nd ed., Plastic Design Library, 2003.

[12] Zeman, S. \& Kubik, L., Permeability of Polymeric Packaging Materials, Technical Sciences, 1(10), pp. 26-34, 2007. DOI 10.2478/v10022-007-0004-6

[13] Kuraray, EVAL ${ }^{T M}$. www.evalevoh.com. Accessed on: 2 May 2020.

[14] Kroschwitz, J.I., Concise Encyclopedia of Polymer Sciences and Engineering, John Wiley \& Sons: New York, 1990. 